\title{
How couples with dementia experience healthcare, lifestyle, and everyday decision-making
}

\author{
Craig Sinclair, ${ }^{1}$ Kate Gersbach, ${ }^{2}$ Michelle Hogan, ${ }^{3}$ Romola S. Bucks, ${ }^{4}$ \\ Kirsten A. Auret, ${ }^{1}$ Josephine M. Clayton, ${ }^{5}$ Meera Agar ${ }^{6}$ and Sue Kurrle ${ }^{7}$ \\ ${ }^{1}$ Rural Clinical School of Western Australia, University of Western Australia, Albany, Australia \\ ${ }^{2}$ Brightwater Care Group, Perth, Australia \\ ${ }^{3}$ Helping Hand Aged Care, Adelaide, Australia \\ ${ }^{4}$ School of Psychological Science, University of Western Australia, Perth, Australia \\ ${ }^{5}$ HammondCare, Sydney Medical School, University of Sydney, Sydney, Australia \\ ${ }^{6}$ University of Technology Sydney, Sydney, Australia \\ ${ }^{7}$ University of Sydney, Sydney, Australia
}

Objectives: Recent research has demonstrated the challenges to self-identity associated with dementia, and the importance of maintaining involvement in decision-making while adjusting to changes in role and lifestyle. This study aimed to understand the lived experiences of couples living with dementia, with respect to healthcare, lifestyle, and "everyday" decision-making.

Design: Semi-structured qualitative interviews using Interpretative Phenomenological Analysis as the methodological approach.

Setting: Community and residential care settings in Australia.

Participants: Twenty eight participants who self-identified as being in a close and continuing relationship ( $N=13$ people with dementia, $N=15$ spouse partners). Nine couples were interviewed together.

Results: Participants described a spectrum of decision-making approaches (independent, joint, supported, and substituted), with these approaches often intertwining in everyday life. Couples' approaches to decisionmaking were influenced by "decisional," "individual," "relational," and "external" factors. The overarching themes of "knowing and being known," "maintaining and re-defining couplehood" and "relational decisionmaking," are used to interpret these experiences. The spousal relationship provided an important context for decision-making, with couples expressing a history and ongoing preference for joint decision-making, as an integral part of their experience of couplehood. However, the progressive impairments associated with dementia presented challenges to maintaining joint decision-making and mutuality in the relationship.

Conclusions: This study illustrates relational perspectives on decision-making in couples with dementia. Postdiagnostic support, education resources, proactive dyadic interventions, and assistance for spouse care partners may facilitate more productive attempts at joint decision-making by couples living with dementia.

Key words: dementia, mental capacity, medical-legal issues, family therapy

\section{Introduction}

The progressive cognitive impairments associated with dementia present ethical challenges for involvement in decision-making, and have prompted significant research and debate (Nuffield Council

\footnotetext{
Correspondence should be addressed to: Craig Sinclair, Rural Clinical School of Western Australia, University of Western Australia, Sydney, Australia. Phone: (+61 8) 9842 0829; Fax: (+61 8) 9842 0879. Email: craig.sinclair@rcswa.edu.au. Received 22 Jan 2018; revision requested 6 Mar 2018; revised version received 22 Mar 2018; accepted 16 Apr 2018. First published online 25 May 2018.
}

on Bioethics, 2009). People with dementia have described involvement in decision-making as an important means of affirming self-identity and confirmation that "I'm still here" (Fetherstonhaugh et al., 2013, p.148), however, most research in this field focuses on the practice of substitute decision-making among family caregivers (Miller et al., 2016), frequently excluding the person with dementia (Larsson and Osterholm, 2014).

The majority of people with dementia live in the community and receive informal support from family caregivers, typically spouse partners 
(Brown et al., 2017). However, research on spousal dynamics in dementia has traditionally considered the couple as two individuals, a "care provider" and a "care receiver" (Hellström et al., 2015), potentially reproducing unhelpful dichotomies (Forbat, 2003). The "couplehood" concept emphasizes the relational perspective, describing the extent to which couples understand themselves as part of a "we" (rather than me-you) relationship (Kaplan, 2001; Hyden and Nilsson, 2015). Couplehood has been conceptualized with respect to the broader experience of dementia (Hellstrom, 2007; Merrick et al., 2016; Wawrziczny et al., 2016; Hernandez et al., 2017), and specific components such as disclosure preferences (Hellström and Torres, 2013) and understandings of the future (Hellström and Torres, 2016).

While the literature exploring couplehood in dementia is growing, there is less research on experiences of decision-making among these couples. Research on decision-making within the couple dyad has described a spectrum of involvement of the person with dementia, with a typical transition toward substitute decision-making, and reliance on the person's past preferences (Samsi and Manthorpe, 2013). Tyrrell et al. (2006) found people with dementia were less satisfied with decision-making processes than family caregivers.

This study aimed to understand the lived experiences of couples in which one partner is diagnosed with dementia, in healthcare, lifestyle, and everyday decision-making. We focused on describing (i) couples' approaches to decision-making and (ii) the factors influencing these approaches, with a view to developing the existing literature on dyadic decision-making among couples affected by dementia, and yielding practical implications for health professionals.

\section{Methods}

This study is part of a larger project investigating healthcare, lifestyle, and everyday decision-making in the context of dementia, and focuses specifically on decision-making within the couple context. This study draws on a subset of interviews from the larger project, combining dyadic interviews with couples, and individual interviews with people living with dementia and partners in carer roles. Dyadic interviews enable fuller engagement with a relational perspective, and in some cases to observe relevant interactions between participants. Given this focus, relational autonomy (Series, 2015) is used as a theoretical perspective to inform the research methods. Interpretative Phenomenological Analysis (IPA) was used as the methodological approach (Smith et al., 2009). The methods were approved by the University of Western Australia Human Research Ethics Committee (RA/4/1/8307).

\section{Sampling and recruitment}

Eligible participants were identified through Dementia Australia consumer networks, two large aged-care organizations, and one community-based dementia respite facility. Participants self-identified as being in a close and continuing relationship, with one member of the couple having a formal diagnosis of dementia. People with dementia of a mild to moderate severity participated in interviews, with staging confirmed by referring professionals (when referred to the study) or partner rating on the Dementia Severity Rating Scale when selfreferred (Clark and Ewbank, 1996). Couples did not necessarily co-reside (although most did). We employed a "process consent" approach to capacity assessment and informed consent (Dewing, 2007) utilizing five stages: preparation and background; establishing basis for consent; obtaining initial consent; monitoring ongoing consent; and feedback and support (McKeown et al., 2010). Informal meetings were used to establish participant preference for undertaking a dyadic or individual interview. Other than two people with dementia who assented verbally and participated via proxy consent, all other participants provided their own written, informed consent. Table 1 shows interview characteristics.

\section{Data collection}

Interviews were conducted by the first author (CS), with open-ended questions to initiate discussion about couples' experiences in making decisions in healthcare, lifestyle, and "everyday" domains. Questions prompted discussion on both past decisions and anticipated future decisions. Interviews lasted between 48 and 132 minutes (average 74 minutes). Twenty eight participants were interviewed ( $N=13$ people with dementia, $N$ $=15$ spouse partners). One of the spouse partners was in a same-sex relationship. Nine couples were interviewed together. Seven participants $(N=4$ people with dementia, $N=3$ partners) participated in both stages of the broader project, and were interviewed twice (separated by $3-5$ months).

\section{Data analysis}

Interviews were audio-recorded and transcribed by a third-party company. Transcripts were checked for accuracy and de-identified. Analysis was undertaken concurrently with data collection by three authors whose backgrounds are in psychology 
Table 1. Characteristics of interview participants.

\begin{tabular}{|c|c|c|c|}
\hline $\begin{array}{l}\text { PERSON WITH DEMENTIA } \\
\text { (AGE, GENDER, BIRTHPLACE) }\end{array}$ & $\begin{array}{l}\text { SPOUSE PARTNER } \\
\text { (AGE, GENDER, BIRTHPLACE) }\end{array}$ & $\begin{array}{l}\text { LIVING } \\
\text { (TYPE, RURALITY) }\end{array}$ & $\begin{array}{l}\text { DIAGNOSIS } \\
\text { (TYPE, YEARS) }\end{array}$ \\
\hline $\begin{array}{l}\text { Derek, } 71 \text { year, Male, England } \\
\text { Susan, } 66 \text { year, Female, Australia } \\
\text { Josie, } 77 \text { year, Female, England } \\
\text { Luke, } 85 \text { year, Male, Australia } \\
\text { Des, } 66 \text { year, Male, England } \\
\text { Kevin, } 57 \text { year, Male, Australia } \\
\text { Sarah, } 71 \text { year, Female, Australia } \\
\text { Andrew, } 86 \text { year Male, Zimbabwe } \\
\text { Sally, } 72 \text { year, Female, Australia } \\
\text { Josie\# } 77 \text { year, Female, England } \\
\text { David, } 63 \text { year, Male, Australia } \\
\text { Vera, } 65 \text { year, Female, Australia } \\
\text { Tony, } 67 \text { year, Male, Australia }\end{array}$ & $\begin{array}{l}\text { June, } 67 \text { year, Female, England } \\
\text { Doug, } 67 \text { year, Male, Australia } \\
\text { Ron, } 76 \text { year, Male, England } \\
\text { Carmen, } 65 \text { year, Female, Australia } \\
\text { Jessica, } 65 \text { year, Female, Australia } \\
\text { Vivian, } 59 \text { year, Female, Singapore } \\
\text { Chris, } 72 \text { year, Male, Spain } \\
\text { Bess, } 81 \text { year, Female, Australia } \\
\text { Trevor, } 78 \text { year, Male, Australia }\end{array}$ & $\begin{array}{l}\text { RACF*, Regional } \\
\text { Home, Regional } \\
\text { Home, Regional } \\
\text { Home, Metropolitan } \\
\text { Home, Metropolitan } \\
\text { Home, Metropolitan } \\
\text { Home, Regional } \\
\text { Home, Regional } \\
\text { Home, Regional } \\
\text { Home, Regional } \\
\text { Home, Regional } \\
\text { Home, Regional } \\
\text { Home, Metropolitan } \\
\text { Home, Metropolitan } \\
\text { Home, Regional } \\
\text { RACF, Regional } \\
\text { Home, Regional } \\
\text { Home, Regional } \\
\text { Home, Regional }\end{array}$ & 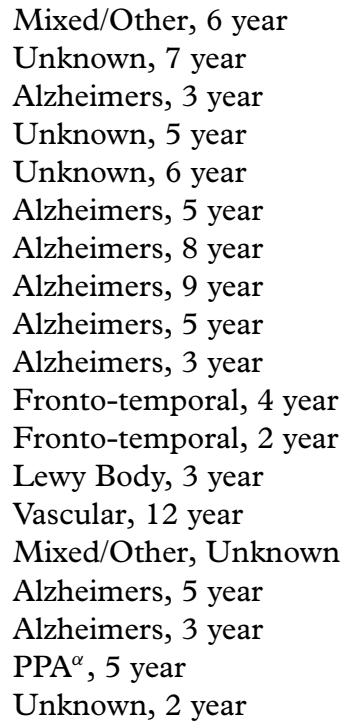 \\
\hline
\end{tabular}

Note:Pseudonyms are assigned for each participant.

\# One interview was planned to be a dyad interview, but undertaken individually, due to spouse partner unavailability at the scheduled time and preference of the person with dementia to continue.

* RACF stands for residential aged care facility.

${ }^{\alpha}$ PPA stands for primary progressive aphasia.

(CS) and nursing (KG, MH). Each transcript was read prior to recording margin notes, including descriptive, conceptual, and linguistic observations (Smith et al., 2009), as well as "dyadic" interactions between the two participants. Each transcript was also summarized individually. The margin notes and transcript summary informed the process of deriving emergent themes, which were organized in a preliminary thematic framework and discussed with other authors to consensus. Additional discussion with the broader team enabled exploration of alternative interpretations and discussion of practical implications of the findings. Emergent themes which were prevalent across the data set, or which had specific explanatory power in relation to salient experiences, were identified as "overarching” themes (Smith, 2011).

\section{Results}

We describe the types of decisions encountered by couples following the diagnosis of dementia, and the factors influencing their approaches to decisionmaking. Three overarching themes are proposed to capture the experience of decision-making for these couples: "knowing and being known;" "maintaining and re-defining couplehood;" and "relational decision-making."

\section{Types of decisions}

Healthcare decisions included those relating to initial help-seeking, establishing diagnosis, navigating healthcare systems, accessing (or refusing) care services, responding to crises (e.g. falls or hospitalizations) and advance care planning. While both partners typically reported a preference for attending appointments with healthcare professionals together, there were some exceptions, including the use of trusted friends, or attending appointments individually.

Lifestyle decisions included living arrangements, employment, civic participation, holidays and outings, pets and important possessions. These decisions were typically made in the context of the couple relationship and family networks, without involving professionals. Decisions about living arrangements dominated many interviews, including re-locating, downsizing, modifying or renovating the home, accessing respite and discussing or accessing residential care.

Everyday decisions related to daily activities undertaken by both partners, separately or together. These included shopping, driving, household maintenance and chores and everyday interactions with family and friends. In the context of leaving paid employment, declining social networks and a reduced scope of activities outside the home, these 
everyday decisions took on extra significance. Some described how one partner had traditionally had responsibility for certain tasks, and how progression of the dementia had required them to adopt unfamiliar roles.

"The responsibility was the worst thing, having to drive the car everywhere, having to make decisions that I hadn't made in the past, financial and to do with cars and men things, what I call men things." (Judith, female partner)

\section{Approaches to decision-making}

Expanding on the spectrum identified by Samsi and Manthorpe (2013), we identified a number of decision-making approaches including independent (made by the person with dementia), joint (made and enacted by both partners on relatively equal basis), supported (person with dementia was assisted), and substitute (partner made the decision). While we envisioned a characteristic approach for each couple, we found that different approaches intertwined, changing with contexts and sometimes within the same decision. As Ron described:

"We start off as a joint thing to talk about what needs deciding but normally [it] ends up with me making the final [decision].” (Ron, male partner)

Couples' approaches to decision-making were influenced by "individual," "relational," "decisional," and "external" factors, which evolved and interacted as the dementia progressed. These are described below and depicted in a conceptual diagram (see Figure 1).

\section{Individual factors}

Individual factors were relevant to both partners, but experienced separately. The stage of the person's dementia, along with daily fluctuations in their energy and self-confidence, influenced both partners' perceptions about the person's ability to be involved. Acceptance of the condition was identified as an important factor, and a process, which sometimes unfolded at different rates for each partner, leading to divergent expectations about involvement in decision-making. Some people with dementia described strong preferences to be involved in, or to delegate decisions (either generally, or specifically for some decisions).

Partners typically understood dementia as a progressive and disabling condition, whose effects could be reduced somewhat through social, emotional, and practical support. While they varied in their skills and experience in the caregiving role, many described efforts to maintain the involvement of the person with dementia in decision-making, through prompting, simplifying information, reducing choices and taking extra time. However, they also described stressful demands and accumulating emotional burden in their informal caregiving role, which impacted on the time and energy available to provide this support.

\section{Relational factors}

Relational factors arose from interactions between partners over time. Relationship quality was described with reference to open communication, mutual contributions, and commitment to the relationship. Couples situated decision-making experiences in broader relational histories, which were typically described as open and harmonious, but in some cases characterized as dominant or dependent. These historical patterns of decisionmaking often required adjustments as the dementia progressed. A sense of "us," as opposed to "me and you," contributed to a relational values system that prioritized outcomes for both partners and considered the impact of decisions on the overall relationship.

\begin{abstract}
"While I can talk about [admission to residential care] now, it's not fair if I get really bad and Doug can't manage, that he feels guilty that he has to try to look after me... [aside to Doug] everybody fights about it, but I'm telling you that that's what you've got to do. Is put me in a home whether I tell you I don't want to then or not." (Susan, female person with dementia)
\end{abstract}

In the context of trust, many people with dementia were willing to delegate decision-making to their partners. Sarah described how she would trust her husband "one hundred percent," and her distress about the possibility of having to delegate to someone other than him.

\section{Decisional factors}

Decisional factors included the characteristics of a decision which influenced the decision-making approach. For some couples, certain decisions were more amenable to involvement of the person with dementia. Some described preferences for involvement in decisions that were personally important to them. In the context of limited time, partners sometimes described investing resources in "important" decisions, and "trading off" on other decisions.

"What we tend to do, depending on the decision, the type of decision and the level of importance there is on 


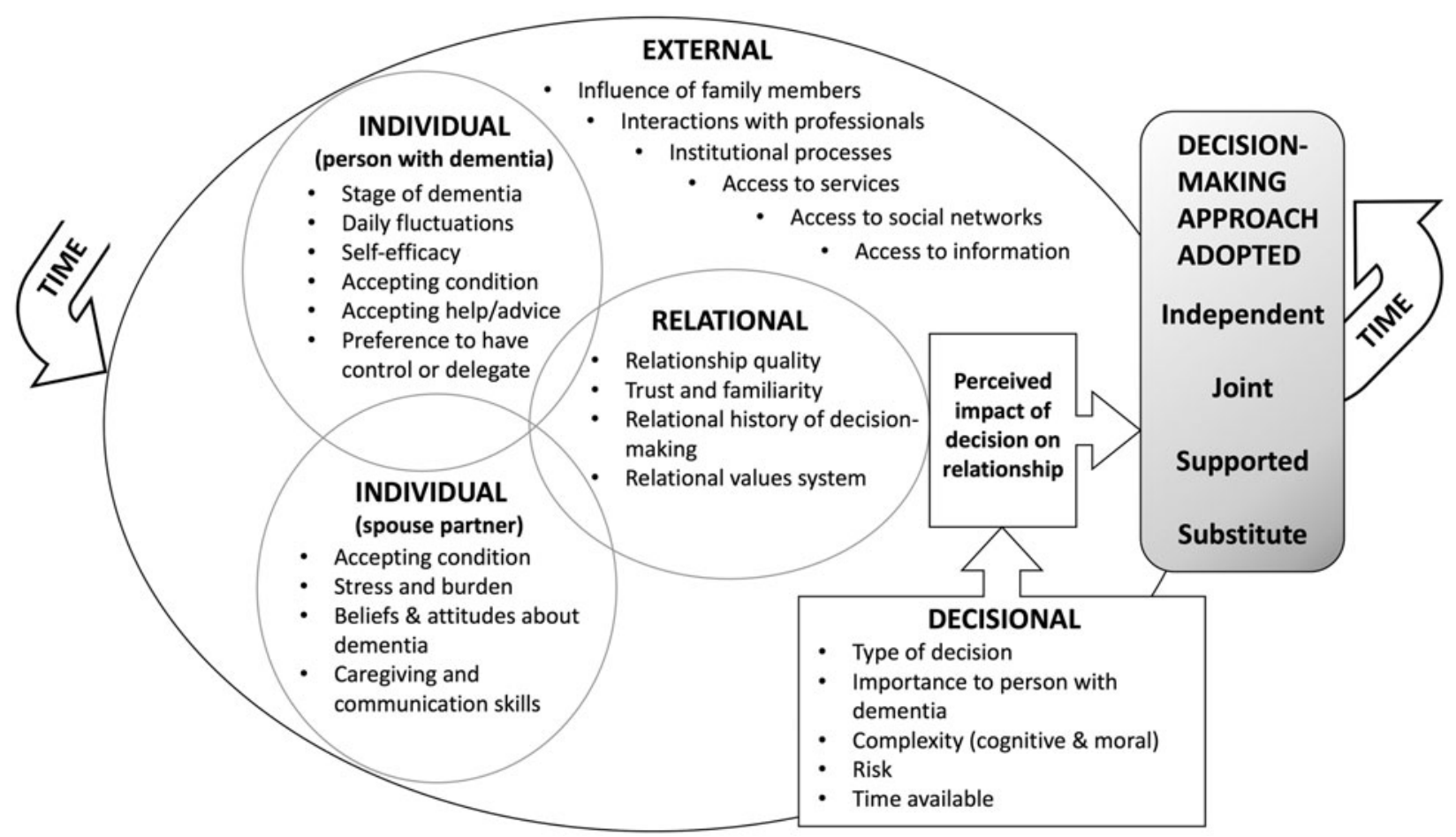

Figure 1. Conceptual diagram of individual, relational, decisional, and external factors, which influenced the decision-making approaches adopted by couples in which one person had a diagnosis of dementia.

him being part of that because some decisions I take on like what we're going to eat for dinner tonight... If we're talking about a decision with regards to him personally, then I do try to engage him." (Vivian, female partner)

Decisions which were cognitively or morally complex, requiring multiple steps or the consideration of ethical dilemmas, tended to require more intensive support, or else were delegated to spouse partners. Risk associated with decisions was understood in physical, financial and emotional terms, and applied to the person with dementia and others. Partners typically monitored such decisions, and felt responsible to intervene and override the person if they felt the risk was unacceptable, or not properly understood by the person. Finally, the time available was also influential; urgent decisions were more often managed unilaterally by spouse partners.

\section{External factors}

Factors external to the couple also influenced decision-making approaches. Couples described being supported and influenced in decision-making by family members, social networks, and key professionals. Health professionals who validated the needs and concerns of both partners, and facilitated joint decision-making, were valued. Contrary to this, some couples identified how admission of one partner to hospital or residential care had disrupted usual patterns of joint decisionmaking, due to institutional processes which excluded the spouse partner and limited their access to information.

"I was well aware before because I used to have to take Derek to his doctors' appointments and I sat there and the doctor would talk to me as well as Derek ... $\mathrm{He}$ is getting visited by the doctor in [residential care facility] but I don't know that because Derek doesn't have any recollection of it. Apparently, he sees them quite frequently but that doesn't get through to me sometimes ... They sort of swallowed it up." (June, female partner).

\section{Overarching themes}

\section{Knowing and being known}

Having access to a trusted and familiar partner was of immense importance to both partners and the prospect of making decisions without the other partner was experienced as threatening. Consistent with previous research (Samsi and Manthorpe, 2013), this sense of "knowing and being known" was associated with greater success by the partner in facilitating involvement of the person with dementia, and a willingness of the person with dementia to delegate decision-making where necessary. A commonly expressed view was 
that the partner "would know the person's wishes," due to the length and closeness of the relationship.

“[Partner]'s very good at knowing what my preferences are to start with..." (David, male person with dementia)

"Just from having an 18-year relationship with him, and discussing things as they've come up over the years... If you have a reasonable quality of a relationship I would imagine that most people would have some idea of those sorts of things." (Vivian, female partner)

While the experience of "knowing and being known" was also evident in other relationships (e.g. children or close friends) some aspects of the couple relationship stood out. A number of couples perceived advance care planning for future healthcare to be redundant, because they knew each other so well. However, contemplation of future scenarios in which the partner was not available (e.g. due to illness or death), raised both partners' awareness of the value of planning for this scenario.

"If I got sick he wouldn't be able to speak for me anymore. I'm the one that needs to put the [advance care directive] in place not him... in fact that would be a reason for him to do it [advance care directive], because if anything suddenly happened to me no-one would know [his wishes], and he may not be able to tell them then. That's a good point. That would be the only reason." (Vivian, female spouse partner)

This suggests that some couples perceived informal, family-based substitute decision-making by the partner as an ideal scenario, with advance care planning being relevant as a "backup."

\section{Maintaining and re-defining couplehood}

Couples' responses evidenced an historical pattern of joint decision-making, with involvement guided by the nature of the decision, gendered roles and relationship dynamics. Following diagnosis of dementia couples attempted to maintain these historical patterns, while acknowledging inevitable transitions.

"...when he's doing his banking on the computer he loses some finances from whichever account and I can't understand what he's doing, but we work through, you know, 'let me sit down and I'll see where you're going and what you're doing'... instead of taking the whole lot off him at this moment because he likes to be the husband and the protector..." (Carmen, female partner)
This finding supports research on couples' decision-making (Samsi and Manthorpe, 2013; Dening et al., 2017), and reflects the dual processes of "holding on and letting go" (Fetherstonhaugh et al., 2013). It can also be understood within broader experiences of maintaining couplehood (Hellstrom, 2007). Merrick et al. found that shared histories provided a "foundation" (2016, p.39), from which couples maintained a sense of couplehood even while roles were changing (Molyneaux et al., 2011). Partners' efforts to support the ongoing contribution of the person with dementia to the relationship (e.g. through established roles as decision-makers in certain domains) may also reflect their desire to avoid an anticipated loss of mutuality (O'Shaughnessy et al., 2010). Consistent with this view, the point at which a person with dementia ceased to have any involvement in decision-making was interpreted by some partners as a turning point, and a source of grief.

“Like I say, we've been together a long time. We've had what I'd call a good marriage. He's a nice guy. Both of us are reasonably patient, tolerant people and it's worked and it's just hard that it's come to this..." (Judith, female partner)

Decisions about living arrangements provided powerful examples of how efforts to maintain and re-define couplehood resulted in different outcomes. For some maintaining the co-residing arrangement at home was the highest priority, and perhaps symbolized couplehood. For others residential care admission was seen as a means of protecting the ongoing relationship, even as living arrangements changed.

"I keep saying I want to go into care sooner rather than later. I want my hubby [sic] to come and visit me. I don't want him to hate me by the time everybody says I've got to be there. I want to be there earlier than that." (Vera, female person with dementia)

Where partners had different understandings about potential changes to living arrangements, this could be a source of tension and conflict.

"...she had banned [the word 'respite'] from our house... By the word respite she understood the thin end of the wedge of admission ended for her in residential aged care. And for me respite was time out, totally different." (Liesel, female partner)

These highly personalized understandings of "home" among people with dementia have been articulated in previous research (Aminzadeh et al., 2009). 


\section{Relational decision-making}

Implicit in couples' decision-making was understanding the impact of decisions on others, in particular the partner. Many people with dementia expressed concern about burdening their partner with care demands, and adopted a relational frame of reference, privileging the relationship over individual concerns. David worried that if his partner ceased employment to provide care, she would struggle to re-enter the workforce, and this would then impact on her wellbeing during her own later years: "that's the sort of burden that you don't want to try and impart." Previous research has suggested that couples with dementia employ relational perspectives, to re-affirm a sense of continuity and stability, in the context of shifting roles and identities (Merrick et al., 2016). This relational perspective also appeared to apply to decision-making within the couple context.

\section{Discussion}

This study explored experiences of decisionmaking among couples in which one person was diagnosed with dementia. The individual and dyadic interviews provided a range of contexts and perspectives on how couples approach decisionmaking in the mild to moderate stages of dementia.

Contrary to assumptions in the ethico-legal literature that involvement in decision-making hinges upon the person's decision-making capacity, we found evidence for a broader set of mutually interacting factors which influenced involvement. While progression of dementia led to transitions in decision-making approaches, these were not linear or predictable. Different decision-making approaches (independent, joint, supported, and substituted) intertwined in everyday life, and were dependent on decisional, individual, relational, and external factors. This reflects the interdependent nature of the couple relationship, and how couples function within broader systems of family, social networks, and services. In the context of stress in the caregiving role, partners may require assistance to manage these transitions in decision-making approaches. The factors articulated here may provide clinicians with a "toolkit" to expand discussions with couples about decision-making approaches, ideally prior to crisis situations.

The dynamics associated with couples' experiences of decision-making appeared to reflect patterns occurring in the broader relationship. This suggests important parallels between decisionmaking in couple relationships and broader experiences of couplehood in dementia. Within the "knowing and known" relationship, the desire to maintain a sense of couplehood in decision-making can be understood as part of the broader process of coping with dementia (Molyneaux et al., 2011). This has implications for a range of decisions, in particular those with direct impacts on, or symbolic significance for, the ongoing relationship (e.g. living arrangements). The potential for divergent understandings between partners about the symbolic significance of a decision, or the options available, suggests that some couples may benefit from dyadic interventions aimed at facilitating communication and providing education and support (e.g. Whitlatch et al., 2006).

The trust and familiarity characterizing most of these relationships enabled partners to support involvement of the person with dementia in decision-making. However, it also led to some unexpected effects, such as the view that the partner would automatically know the person's wishes, a sentiment which is challenged by existing research (Reamy et al., 2011). Some couples also felt their close relationship meant that advance care planning was redundant. These couples might perceive advance care planning as more relevant if it were reframed from a relational perspective, considering future scenarios in which either partner was incapacitated. Where health professionals included partners and facilitated joint decision-making, this was valued by both members of the couple. We suggest that care transitions (e.g. hospital or residential care admission) should also prompt consideration of couples' historical and preferred decision-making approaches, with a view to maintaining joint decision-making where possible.

This study has some limitations to consider. The participants were predominantly from AngloAustralian ethnic backgrounds, and living in heterosexual relationships. The sampling strategy may have biased recruitment towards couples with more functional relationships, or higher levels of self-awareness regarding decision-making approaches. Future research employing more diverse samples may articulate additional considerations in decision-making. Only seven participants undertook follow up interviews, limiting the extent to which a longitudinal perspective can be applied.

\section{Conclusion}

This study has illustrated how dyadic decisionmaking is experienced among couples in which one partner is diagnosed with dementia, and informs the broader experience of couplehood in dementia. Involvement in decision-making was sensitive to a range of contextual factors, not just 
the person's "decision-making capacity." Health professionals should consider both partners' needs and facilitate efforts to maintain joint decisionmaking with sensitivity to the dynamics of the couple relationship and disease progression. Future research should explore the extent to which postdiagnostic support, education resources, proactive dyadic interventions, and assistance for partners may facilitate more productive attempts at joint decision-making by couples living with dementia.

\section{Conflict of interest}

None.

\section{Description of author's roles}

C. Sinclair formulated the question, designed the study, conducted the interviews, participated in data analysis, and drafted the manuscript. K. Gersbach and $M$. Hogan participated in data analysis and assisted in drafting the manuscript. R. Bucks and K. Auret contributed to the study design, supervised the data analysis and critically reviewed the manuscript. J. Clayton, M. Agar and S. Kurrle contributed to the study design and critically reviewed the manuscript.

\section{Acknowledgments}

The authors wish to thank the participants involved, and to acknowledge Dementia Australia, Brightwater Care Group, Helping Hand Aged Care, and HammondCare for facilitating the process of recruitment to the study. The authors would also like to acknowledge the contribution of organizations and individuals who have contributed to advisory groups associated with this project. These include consumer representatives (Kathy Williams, Ann Pietsch, Theresa Flavin, Mike Barry, Vicki Barry, Ron Sinclair, Cate McCullough, Karine Shellshear, Darcelle Wu), and organizations (NSW Office of the Public Guardian, SA Office of the Public Advocate, SA Government Department of Communities and Social Inclusion, Dementia Australia, Alzheimers WA, Carers Australia (NSW, SA), Leading Aged Services Australia NSW, Australian Aged Care Quality Agency, Council on the Ageing (SA), NSW Elder Abuse Helpline \& Resource Unit, Seniors Rights Services NSW, Advocare, Partners in Culturally Appropriate Care (NSW), Multicultural Aged Care (SA)). Advisory group members did not determine the study design, or have access to raw data. Participation in advisory groups does not imply endorsement of the study findings by these individuals or organizations. The authors also acknowledge the contribution of Funding Bodies (National Health \& Medical Research Council) and Funding Partners (Dementia Australia, HammondCare, Helping Hand Aged Care, Brightwater Group). The contents of the above materials are solely the responsibility of the individual authors identified, and do not reflect the views of the Funding Bodies or the Funding Partners. This research was funded by the NHMRC Partnership Centre: Dealing with Cognitive and Related Functional Decline in Older People (Cognitive Decline Partnership Centre). The funding bodies had no role in determining the design of the study, data collection, data analysis, write-up, or decision to publish.

\section{References}

Aminzadeh, F., Dalziel, W. B., Molnar, F. J. \& Garcia, L. J. (2009). Symbolic meaning of relocation to a residential care facility for persons with dementia. Aging $\mathcal{E}$ Mental Health, 13, 487-496. doi:10.1080/13607860802607314.

Brown, L., Hansnata, E. and La, H. A. (2017). Economic Cost of Dementia in Australia 2016-2056. Canberra: University of Canberra.

Clark, C. M. and Ewbank, D. C. (1996). Performance of the dementia severity rating scale: a caregiver questionnaire for rating severity in Alzheimer disease. Alzheimer Disease and Associated Disorders, 10, 31-39. doi:10.1097/00002093-199601010-00006.

Dening, K. H., King, M., Jones, L. and Sampson, E. L. (2017). Healthcare decision-making: past, present and future, in light of a diagnosis of dementia. International Fournal of Palliative Nursing, 23, 4-11. doi:10.7748/nop.29.3.13.s16.

Dewing, J. (2007). Participatory research: a method for process consent with persons who have dementia. Dementia - The International fournal of Social Research and Practice, 6, 11-25. doi:10.1177/1471301207075625.

Fetherstonhaugh, D., Tarzia, L. and Nay, R. (2013). Being central to decision making means I am still here!: the essence of decision making for people with dementia. Fournal of Aging Studies, 27, 143-150. doi:10.1016/j.aging.2012.12.007.

Forbat, L. (2003). Relationship difficulties in dementia care. Dementia, 2, 67-84. doi:10.1177/14713012030021995.

Hellström, I. (2007). Sustaining 'couplehood': spouses' strategies for living positively with dementia. Dementia The International Fournal of Social Research and Practice, 6, 383-409. doi:10.1177/1471301207081571.

Hellström, I., Eriksson, H. and Sandberg, J. (2015). Chores and sense of self: gendered understandings of voices of older married women with dementia. International fournal of Older People Nursing, 10, 127-135.

Hellström, I. and Torres, S. (2013). A wish to know but not always tell - couples living with dementia talk about 
disclosure preferences. Aging $\mathcal{E}$ Mental Health, 17, 157-167. doi:10.1080/13607863.2012.742491.

Hellström, I. and Torres, S. (2016). The "not yet" horizon: understandings of the future amongst couples living with dementia. Dementia - The International fournal of Social Research and Practice, 15, 1562-1585. doi: $10.1177 / 1471301214565673$.

Hernandez, E., Spencer, B., Ingersoll-Dayton, B., Faber, A. and Ewert, A. (2017). "We are a team": couple identity and memory loss. Dementia - The International fournal of Social Research and Practice, 0, 1-15, doi:10.1177/1471301217709604.

Hyden, L. and Nilsson, E. (2015). Couples with dementia: positioning the 'we'. Dementia - The International fournal of Social Research and Practice, 14, 716-733.

Kaplan, L. (2001). A couplehood typology for spouses of institutionalized persons with Alzheimer's disease: perceptions of "We"-“I”. Family Relations, 50, 87-98. doi:10.1111/j.1741-3729.2001.00087.x.

Larsson, A. T. and Osterholm, J. H. (2014). How are decisions on care services for people with dementia made and experienced? A systematic review and qualitative synthesis of recent empirical findings. International Psychogeriatrics, 26, 1849-1862. doi:10.1017/s104161021400132x.

McKeown, J., Clarke, A., Ingleton, C. and Repper, J. (2010). Actively involving people with dementia in qualitative research. Fournal of Clinical Nursing, 19, 1935-1943. doi:10.1111/j.1365-2702.2009.03136.x.

Merrick, K., Camic, P. M. and O'Shaughnessy, M. (2016). Couples constructing their experiences of dementia: a relational perspective. Dementia - The International fournal of Social Research and Practice, 15, 34-50. doi:10.1177/1471301213513029.

Miller, L. M., Whitlatch, C. J. and Lyons, K. S. (2016). Shared decision-making in dementia: a review of patient and family carer involvement. Dementia - The International Fournal of Social Research and Practice, 15, 11411157.

Molyneaux, V. J., Butchard, S., Simpson, J. and Murray, C. (2011). The co-construction of couplehood in dementia. Dementia - The International fournal of Social
Research and Practice, 11, 483-502. doi: $10.1177 / 1471301214555542$.

Nuffield Council on Bioethics (2009). Dementia: Ethical Issues. London: Nuffield Council of Bioethics.

O'Shaughnessy, M., Lee, K. and Lintern, T. (2010). Changes in the couple relationship in dementia care: spouse carer's experiences. Dementia - The International fournal of Social Research and Practice, 9, 237-258.

Reamy, A. M., Kim, K., Zarit, S. H. and Whitlatch, C. J. (2011). Understanding discrepancy in perceptions of values: individuals with mild to moderate dementia and their family caregivers. Gerontologist, 51, 473-483. doi:10.1093/geront/gnr010.

Samsi, K. and Manthorpe, J. (2013). Everyday decision-making in dementia: findings from a longitudinal interview study of people with dementia and family carers. International Psychogeriatrics, 25, 949-961. doi:10.1017/s1041610213000306.

Series, L. (2015). Relationships, autonomy and legal capacity: mental capacity and support paradigms. International fournal of Law and Psychiatry, 40, 80-91. doi:10.1016/j.ijlp.2015.04.010.

Smith, J. A. (2011). Evaluating the contribution of interpretative phenomenological analysis. Health Psychology Review, 5, 9-27. doi:10.1080/17437199.2010.510659.

Smith, J. A., Flowers, P. and Larkin, M. (2009). Interpretative Phenomenological Analysis: Theory, Method and Research. Los Angeles: Sage.

Tyrell, J., Genin, N. and Myslinski, M. (2006). Freedom of choice and decision-making in health and social care. Dementia - The International fournal of Social Research and Practice, 5, 479-502. doi:10.1177/1471301206069915.

Wawrziczny, E., Antoine, P., Ducharme, F., Kergoat, M. J. and Pasquier, F. (2016). Couples' experiences with early-onset dementia: an interpretative phenomenological analysis of dyadic dynamics. Dementia - The International Fournal of Social Research and Practice, 15, 1082-1099. doi:10.1177/1471301214554720.

Whitlatch, C. J., Judge, K., Zarit, S. H. and Femia, E. (2006). Dyadic intervention for family caregivers and care receivers in early-stage dementia. Gerontologist, 46, 688-694. doi:10.1093/geront/46.5.688. 